\title{
Higher Serum Total Cholesterol Levels are Associated With Better Long-Term Balance Function After First-Time Ischemic Stroke
}

\author{
Hung-Pin Lee ${ }^{\mathrm{a}}$, Yen-Ho Wang ${ }^{\mathrm{b}, \mathrm{c}}$, Ching-Lin Hsieh ${ }^{\mathrm{d}}$, Yih-Tsen Lai ${ }^{\mathrm{b}, \mathrm{e}}$, Shin-Liang Pan ${ }^{\mathrm{b}, \mathrm{c}, \mathrm{f}}$
}

\begin{abstract}
Background: To investigate the effects of serum total cholesterol (TC) on long-term balance function in patients with first-time ischemic stroke.

Methods: A total of 99 patients with first-time ischemic stroke were enrolled. The participants were divided into two groups according to TC levels: high TC $(\geq 5.17 \mathrm{mmol} / \mathrm{L})$ and low TC $(<$ $5.17 \mathrm{mmol} / \mathrm{L}$ ). Balance function was measured using the Postural Assessment Scale for Stroke Patients (PASS) at 2 weeks (baseline) and 1, 3, 6, and 12 months after stroke. Prognostic factors affecting the repeated measurements of the PASS score were evaluated using linear mixed regression analysis.
\end{abstract}

Results: TC levels, baseline PASS score, age, sex, and follow-up time were identified as significant prognostic factors of the longterm PASS score. The high TC group had higher PASS scores (estimated parameter $1.57,95 \% \mathrm{CI}: 0.58,2.55)$ than the low TC group. An increase of one unit in the baseline PASS score led to a 0.65 unit increase (95\% CI: $0.61,0.70)$ in subsequent PASS scores. Age was negatively correlated with the PASS scores, with a 0.12 unit decrease $(95 \%$ CI: $-0.16,-0.07)$ for a 1 year increase in age. Women had PASS scores that were 2.63 units lower (95\% CI: -3.70, -1.57)

Manuscript accepted for publication August 7, 2012

${ }^{a}$ Department of Physical Medicine and Rehabilitation, National Taiwan University Hospital, Yun-Lin Branch, Yunlin, Taiwan

${ }^{\mathrm{b}}$ Department of Physical Medicine and Rehabilitation, National Taiwan University Hospital, Taipei, Taiwan

${ }^{\mathrm{c}}$ Department of Physical Medicine and Rehabilitation, College of

Medicine, National Taiwan University, Taipei, Taiwan

${ }^{\mathrm{d}}$ School of Occupational Therapy, College of Medicine, National Taiwan

University, Taipei, Taiwan

eDepartment of Physical Medicine and Rehabilitation, Cathay General Hospital, Taipei, Taiwan

${ }^{\mathrm{f}}$ Corresponding author: Shin-Liang Pan, Department of Physical Medicine and Rehabilitation, National Taiwan University Hospital and National Taiwan University College of Medicine, No. 7, Chung Shan South Rd., Taipei 100, Taiwan.

Email: panslcb@gmail.com

doi: http://dx.doi.org/10.4021/jnr130w than men.

Conclusions: Higher serum TC levels measured during the acute stage of first-time ischemic stroke are a favorable prognostic factor for long-term balance function.

Keywords: Cholesterol; Stroke; Rehabilitation; Postural balance; Risk factors

\section{Introduction}

Stroke-related neurological deficits and disability are an enormous burden to healthcare systems, underscoring the importance of predicting outcomes during the early stage of stroke [1]. While high serum total cholesterol (TC) levels have been shown to increase the risk of coronary artery disease [2], the association between hypercholesterolemia and stroke remains controversial [3-8]. Moreover, several previous studies have pointed out the paradoxical finding that higher serum TC levels are related to lower mortality after stroke [9-12]. Zuliani et al [11] reported that stroke patients with low serum TC levels have higher short-term mortality and Olsen et al [12] showed that higher TC levels are associated with less severe stroke and a higher ten-year survival. In contrast, several groups failed to demonstrate such a favorable prognostic effect of high TC levels in stroke patients [13-15]. These conflicting findings may be partly explained by heterogeneity within and across study populations $[9,14]$. Since cholesterol might play different roles in ischemic stroke and hemorrhagic stroke [16], it is necessary to evaluate outcome in a more homogeneous population (e.g. individuals with first-time ischemic stroke). In addition, most previous studies on the prognostic role of TC on stroke evaluated mortality [9-12, 14, 15] or short-term disability $[10,17]$ as the outcome measure. Little is known about the relationship between serum TC levels and longterm functional performance in stroke survivors. To the best of our knowledge, no study has specifically evaluated the prognostic value of serum TC levels on balance function in a stroke population. The Postural Assessment Scale for Stroke 
Table 1. Demographic and Clinical Characteristics of the Participants Stratified by Total Cholesterol Level

\begin{tabular}{|c|c|c|c|}
\hline Variables & $\begin{array}{c}\text { HTC group } \\
\quad(n=54)\end{array}$ & $\begin{array}{l}\text { LTC group } \\
\quad(n=45)\end{array}$ & P value \\
\hline Age, y & $68.3 \pm 9.7$ & $65.0 \pm 11.8$ & 0.130 \\
\hline Women & $23(42)$ & $13(29)$ & 0.158 \\
\hline Baseline PASS score & $20.1 \pm 11.5$ & $19.0 \pm 11.0$ & 0.788 \\
\hline Diabetes mellitus & $20(37)$ & $13(29)$ & 0.392 \\
\hline Coronary artery disease & $11(20)$ & $6(13.3)$ & 0.355 \\
\hline Left side lesion & $32(59)$ & $27(60)$ & 0.940 \\
\hline Basal ganglion lesion & $24(44)$ & $15(33)$ & 0.353 \\
\hline Large infarct & $43(80)$ & $37(82)$ & 0.297 \\
\hline Glucose, $\mathrm{mmol} / \mathrm{L}$ & $7.69 \pm 2.86$ & $6.92 \pm 3.17$ & 0.260 \\
\hline Albumin, g/L & $37 \pm 3$ & $36 \pm 5$ & 0.516 \\
\hline Creatinine, $\mu \mathrm{mol} / \mathrm{L}$ & $78.68 \pm 21.22$ & $84.87 \pm 26.52$ & 0.234 \\
\hline
\end{tabular}

The values are expressed as the number (\%) or the mean \pm standard deviation. Abbreviations: PASS: Postural Assessment Scale for Stroke Patients; HTC, high total cholesterol ( $\geq 5.17 \mathrm{mmol} / \mathrm{L})$; LTC, low total cholesterol $(<5.17 \mathrm{mmol} / \mathrm{L})$.

patient (PASS), a clinical assessment of postural control in stroke patients, has been proven to be a valid indicator of functional recovery in stroke patients [18-21]. In this study, we investigated the effect of serum TC levels on long-term PASS scores in patients with first-time ischemic stroke. Such information should be very informative in clinical consultation and rehabilitation planning.

\section{Methods}

The data were taken from the registry of the "Quality of Life after Stroke Study" (QLSS) for the period between November, 1999 and November, 2001. The QLSS is a prospective cohort study of stroke patients admitted to the National Taiwan University Hospital (NTUH) and the details of the QLSS have been described elsewhere [18]. The study was approved by the National Taiwan University Hospital (NTUH) Research Ethics Committee. Written informed consent was obtained from each participant. Patients were included if they met the following criteria: (1) first-time diagnosis of ischemic stroke defined according to the International Classification of Disease, 9th Revision, clinical Modification codes of cerebral infarction (434) or others $(433,436,437)$; (2) arrival at the hospital within 14 days after stroke onset; (3) able to obey commands; and (4) signed informed consent. A total of 99 patients with first-time ischemic stroke were enrolled.

As the outcome measure, we used the PASS, which con- 


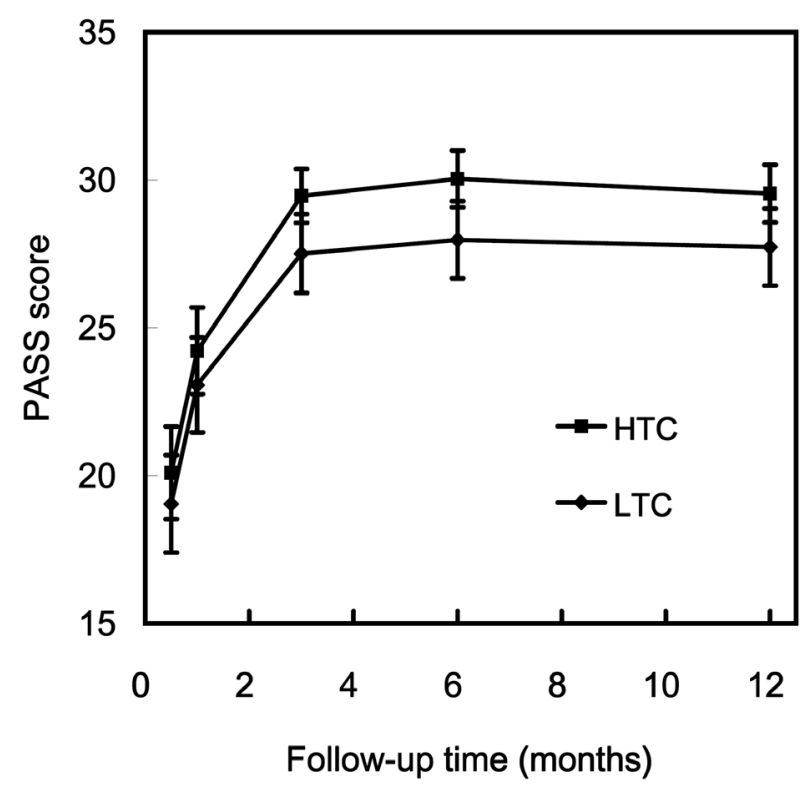

Figure 1. PASS scores during follow-up after stroke. The data are presented as the mean \pm SEM. Abbreviations: HTC, high total cholesterol $(\geq 5.17 \mathrm{mmol} / \mathrm{L})$; LTC, low total cholesterol (<5.17 mmol/L); PASS, Postural Assessment Scale for Stroke Patients.

sists of 12 four-level items that are used to grade performance in maintaining or changing a given posture in situations of varying difficulty $[19,21]$. The total PASS score ranges from 0 to 36 , with a higher score indicating a better balance function [19]. Each patient underwent repeated PASS measurements at 2 weeks (baseline), 1 month, 2 months, 6 months, and 1 year after stroke. One occupational therapist, who was blinded to the laboratory data, administered the PASS to all patients. All subjects underwent a regular rehabilitation training program during hospitalization, including physical therapy, occupational therapy, and nurse support. The size of the infarct was determined by the largest diameter of the lesion on neuroimages, such as computerized tomography and magnetic resonance imaging. Laboratory examinations, including serum TC and other biochemical tests, were performed in the same laboratory of the NTUH within two weeks after stroke onset. Serum levels of TC and albumin were measured using an automatic biochemical analyzer (Hitachi 7450; Hitachi, Tokyo, Japan). The concentration of plasma glucose was measured using an autoanalyzer (Hitachi 7170; Hitachi Corp., Tokyo, Japan).

We evaluated the association between serum TC levels and long-term balance function after ischemic stroke. Other factors that were evaluated in the analysis included demographic factors (age and sex), medical comorbidities (diabetes mellitus and coronary artery disease), biochemical variables (glucose and albumin levels), infarct location, infarct size, and laterality of brain lesions. Because basal ganglia lesions may be associated with an unfavorable functional outcome [22], we grouped the location of the infarct according to involvement of the basal ganglion. Lesions greater than 1 $\mathrm{cm}$ in size were defined as large infarcts.

\section{Statistical method}

The participants were grouped into the high TC (HTC, total cholesterol $\geq 5.17 \mathrm{mmol} / \mathrm{L}$ ) and low TC (LTC, total cholesterol $<5.17 \mathrm{mmol} / \mathrm{L}$ ) groups. Demographic and clinical characteristics were compared between the groups using Student's $t$ test for interval variables and the chi-square test for categorical variables. The linear mixed regression model was used to analyze the effects of various prognostic factors on the repeated measurements of the PASS. Because the rate of functional recovery following stroke tended to be initially faster, then decrease with time, a natural logarithm transformation was applied to the follow-up time as $\log$ (days) for approximating a linear relationship between the PASS score and follow-up time. The statistical criterion for eliminating the variable from the stepwise analysis was a significance level $>0.10$. An alpha level of 0.05 was considered statistically significant for all analyses. The analysis was carried out using SAS software (release 9.1, SAS Institute Inc, Cary, $\mathrm{NC})$.

\section{Results}

Table 1 shows the demographic and clinical characteristics of the subjects, stratified by TC levels. The mean TC levels were $6.04 \mathrm{mmol} / \mathrm{L}$ for the HTC group and $4.41 \mathrm{mmol} / \mathrm{L}$ 
Table 2. Analysis of Prognostic Factors Affecting Repeated Measurements of the PASS Score Using a Linear Mixed Regression Model

\section{Regression coefficients}

\begin{tabular}{|c|c|c|c|c|}
\hline \multirow{2}{*}{ Variable $^{\dagger}$} & \multirow[b]{2}{*}{$\begin{array}{l}\text { Crude } \\
(95 \% \text { CI })\end{array}$} & \multirow{2}{*}{\multicolumn{2}{|c|}{$\begin{array}{l}\text { Multiple } \\
\text { regression } \\
(95 \% \mathrm{CI})\end{array}$}} & \multirow[b]{2}{*}{ P value } \\
\hline & & & & \\
\hline Follow-up time in $\log$ (days) & $\begin{array}{c}2.94 \\
(2.24,3.65)\end{array}$ & $<0.0001$ & $\begin{array}{c}2.94 \\
(2.53,3.35)\end{array}$ & $<0.0001$ \\
\hline Age (year) & $\begin{array}{c}-0.15 \\
(-0.23,-0.08)\end{array}$ & $<0.0001$ & $\begin{array}{c}-0.12 \\
(-0.16,-0.07)\end{array}$ & $<0.0001$ \\
\hline Sex (female vs. male) & $\begin{array}{c}-1.92 \\
(-3.65,0.18)\end{array}$ & 0.031 & $\begin{array}{c}-2.63 \\
(-3.70,-1.57)\end{array}$ & $<0.0001$ \\
\hline Baseline PASS score & $\begin{array}{c}0.66 \\
(0.61,0.70)\end{array}$ & $<0.0001$ & $\begin{array}{c}0.65 \\
(0.61,0.70)\end{array}$ & $<0.0001$ \\
\hline Total cholesterol (HTC vs. LTC) & $\begin{array}{c}2.01 \\
(0.32,3.69)\end{array}$ & 0.020 & $\begin{array}{c}1.57 \\
(0.58,2.55)\end{array}$ & 0.002 \\
\hline Lesion laterality (left vs. right) & $\begin{array}{c}0.18 \\
(-1.52,1.88)\end{array}$ & 0.831 & ND & ND \\
\hline Basal ganglion lesion (yes vs. no) & $\begin{array}{c}-1.40 \\
(-3.14,0.35)\end{array}$ & 0.118 & ND & ND \\
\hline Lesion size ( $\geq 1 \mathrm{~cm}$ vs. $<1 \mathrm{~cm})$ & $\begin{array}{c}-6.33 \\
(-8.74,-3.92)\end{array}$ & $<0.0001$ & ND & ND \\
\hline Diabetes mellitus (yes vs. no) & $\begin{array}{c}-0.88 \\
(-2.63,0.87)\end{array}$ & 0.325 & ND & ND \\
\hline Coronary artery disease (yes vs. no) & $\begin{array}{c}-2.39 \\
(-4.57,-0.21)\end{array}$ & 0.032 & ND & ND \\
\hline $\operatorname{Albumin}(<35$ vs. $\geq 35 \mathrm{~g} / \mathrm{L})$ & $\begin{array}{c}-0.96 \\
(-3.12,1.20)\end{array}$ & 0.386 & ND & ND \\
\hline Glucose $(\geq 11.1$ vs. $<11.1 \mathrm{mmol} / \mathrm{L})$ & $\begin{array}{c}-2.76 \\
(-5.48,-0.05)\end{array}$ & 0.047 & ND & ND \\
\hline
\end{tabular}

*Only adjusted for follow-up time. The value or group on the right-hand side of each comparison is the reference group. Abbreviations: PASS, Postural Assessment Scale for Stroke Patients; HTC, high total cholesterol ( $\geq 5.17 \mathrm{mmol} / \mathrm{L})$; LTC, low total cholesterol $(<5.17 \mathrm{mmol} / \mathrm{l})$; ND, no data.

for the LTC group. The follow-up rates for the HTC and LTC groups at the end of the study were $91 \%$ and $92 \%$, respectively. There was no significant difference between the
HTC and LTC groups in demographic variables (age, sex) or clinical variables (baseline PASS score, diabetes mellitus, coronary artery disease, infarct laterality, infarct size, basal 
ganglion infarct, glucose, and albumin).

Figure 1 shows the changes in the PASS score with time for the LTC and HTC groups. For both groups, the PASS score increased rapidly in the first three months, then reached a plateau. The HTC group had a higher mean PASS score than the LTC group at all time points, showing that subjects with higher TC levels have better postural control after stroke.

The results of linear mixed regression analysis for the repeated measurements of the PASS score are presented in Table 2 . The estimate of the crude effect (only adjusted for the follow-up time) of each variable analyzed is shown on the left and the adjusted parameter estimates of the final multiple regression model on the right. TC levels $(\mathrm{P}=0.0020)$, follow-up time $(\mathrm{P}<0.0001)$, age $(\mathrm{P}<0.0001)$, sex $(\mathrm{P}<0.0001)$, and baseline PASS score $(\mathrm{P}<0.0001)$ were significant prognostic factors for the serial PASS scores in the final multiple regression model. Other independent variables, including lesion laterality, infarct location, infarct size, diabetes mellitus, coronary heart disease, glucose, and albumin had no significant effect on the PASS score in the multiple regression analysis. For the continuous variables (age, baseline PASS score, and follow-up time), the estimated parameters indicate the magnitude of the change in subsequent PASS scores for each 1 unit change in the corresponding variable. For the categorical variables (sex and cholesterol), the estimated parameters represent the differences in PASS scores compared to the reference group (Table 2).

TC levels had a significant positive effect on the serial measurements of the PASS score. The HTC group had better balance function (estimated parameter 1.57, 95\% CI: 0.58 , $2.55)$ than the LTC group. PASS scores increased with follow-up time, with an increase of one unit of log-transformed day correlating with an increase of 2.94 units (95\% CI: 2.53, 3.35 ) in the PASS score. An increase of one unit in the baseline PASS score correlated with an increase of 0.65 units in subsequent PASS scores (95\% CI: 0.61, 0.70). Age and sex were significant predictors of PASS: older subjects had lower PASS scores with an estimate of a decrease of 0.12 units in the PASS scores $(95 \%$ CI: $-0.16,-0.07)$ for a 1 year increase in age, while women had PASS scores 2.63 units lower than men (95\% CI: $-3.70,-1.57)$.

\section{Discussion}

The main finding of our study was that high serum TC levels measured during the acute stage of stroke were significantly correlated with better long-term balance function in patients with first-time ischemic stroke. The favorable effects of TC remained significant after controlling for other prognostic factors. There are no established biologically plausible mechanisms to explain the finding that higher serum TC levels correlate with higher long-term PASS scores in patients with first-time ischemic stroke. However, we propose several explanations below.

Firstly, cholesterol has been reported to have a neuroprotective effect because of its anti-oxidative properties [23, 24]. Bastiaanse et al [25] found that high cholesterol levels enhance the adaptation of cardiac myocytes to ischemia in vitro, while Joseph et al [24] demonstrated that high cholesterol levels reduce oxidative stress for brain tissue in vitro. When brain tissues undergo ischemic insult, the neural cells produce free radicals, which destroy the lipid bilayer of cell membranes, and cholesterol may serve as a buffer to neutralize the free radicals and protect brain tissues from ischemic injury.

Another possible explanation is that higher serum TC levels could be associated with minor ischemic stroke, which may result in better long-term postural control. Amarenco et al [26] found that lacunar stroke is associated with higher serum cholesterol and, more recently, Olsen et al [12] reported that higher TC levels are associated with less severe stroke. However, this hypothesis may not explain the favorable prognostic effect of high TC levels seen in our study, because the proportion of large infarcts and the baseline PASS scores, both of which indicate initial stroke severity, did not differ significantly between the HTC and LTC groups. Moreover, the effects of TC levels remained significant after controlling for the influences of infarct size and baseline PASS scores.

Finally, low serum TC levels may reflect poor nutrition and health status, which could account for the unfavorable outcomes associated with low TC levels. Kronmal et al [27] and Weverling-Rijnsburger et al [28] found that the all-cause mortality was higher in old patients with low cholesterol and suggested that low TC levels could be accompanied by frailty. However, in the present study, there was no significant difference in serum albumin levels or medical comorbidities between the HTC and LTC groups. These findings do not support the idea that the association between low TC and poor postural control was due to poor general health status or malnutrition.

In addition to TC levels, we found that baseline PASS score, age, and sex were significant prognostic factors for long-term balance function. The baseline PASS score, which represents the initial balance function after stroke, significantly affected subsequent PASS scores. It should be noted that TC levels remained a significant independent predictor after adjusting for the baseline PASS score. Older age has been reported to correlate with poor long-term functional outcome after stroke [29-35] and our study also showed that older participants had poorer balance function. One possible explanation is that older patients may have higher risk of complications and a lower potential for neural reorganization after stroke, which could lead to unfavorable functional outcomes [33].

We also found that women had significantly poorer balance function than men. The prognostic role of sex on 
functional outcomes after stroke has been debated in the literature [36-40]. Further studies are required to clarify this association.

\section{Study Limitations}

Detailed information on statin use before and after stroke was lacking in our study. Nevertheless, in most clinical practice, only patients with high TC levels would take statins for the secondary prevention of ischemic stroke. However, such therapeutic intervention for hypercholesterolemia would be expected to weaken the association between high TC levels measured during the early stage of stroke and the long-term functional outcome, as cholesterol levels in the HTC patients will decrease after initiating statin therapy. We therefore believe that the significant association between high TC levels and better long-term motor recovery seen in the present study would hold even with statin use. In addition, this study only recruited stroke patients from a single medical center, which limits the applicability of our findings.

\section{Conclusions}

The present study showed that patients with higher serum TC levels have better long-term balance function after firsttime ischemic stroke. Nevertheless, because the main purpose of this study was to identify early predictors for longterm balance function after stroke, we cannot conclude that maintaining high serum levels of TC after ischemic stroke will improve balance function. Further studies are needed to investigate the mechanisms underlying the association between TC levels and balance function after ischemic stroke.

\section{Acknowledgement}

This study was supported by grants NSC 89-2314-B-002460 and NSC 90-2314-B-002-325 from the National Science Council, Taiwan.

\section{Conflict of Interest and Funding Disclosure}

None.

\section{References}

1. Spratt N, Wang Y, Levi C, Ng K, Evans M, Fisher J. A prospective study of predictors of prolonged hospital stay and disability after stroke. J Clin Neurosci. 2003;10(6):665-669.

2. Castelli WP, Anderson K, Wilson PW, Levy D. Lipids and risk of coronary heart disease. The Framingham
Study. Ann Epidemiol. 1992;2(1-2):23-28.

3. Landau WM. Is cholesterol a risk factor for stroke?: No. Arch Neurol. 1999;56(12):1521-1524.

4. Amarenco P. Hypercholesterolemia, lipid-lowering agents, and the risk for brain infarction. Neurology. 2001;57(5 Suppl 2):S35-44.

5. Goldstein LB, Adams R, Alberts MJ, Appel LJ, Brass LM, Bushnell CD, Culebras A, et al. Primary prevention of ischemic stroke: a guideline from the American Heart Association/American Stroke Association Stroke Council: cosponsored by the Atherosclerotic Peripheral Vascular Disease Interdisciplinary Working Group; Cardiovascular Nursing Council; Clinical Cardiology Council; Nutrition, Physical Activity, and Metabolism Council; and the Quality of Care and Outcomes Research Interdisciplinary Working Group: the American Academy of Neurology affirms the value of this guideline. Stroke. 2006;37(6):1583-1633.

6. Cholesterol, diastolic blood pressure, and stroke: 13,000 strokes in 450,000 people in 45 prospective cohorts. Prospective studies collaboration. Lancet. 1995;346(89918992):1647-1653.

7. Iso H, Jacobs DR, Jr., Wentworth D, Neaton JD, Cohen JD. Serum cholesterol levels and six-year mortality from stroke in 350,977 men screened for the multiple risk factor intervention trial. N Engl J Med. 1989;320(14):904910.

8. Benfante R, Yano K, Hwang LJ, Curb JD, Kagan A, Ross W. Elevated serum cholesterol is a risk factor for both coronary heart disease and thromboembolic stroke in Hawaiian Japanese men. Implications of shared risk. Stroke. 1994;25(4):814-820.

9. Dyker AG, Weir CJ, Lees KR. Influence of cholesterol on survival after stroke: retrospective study. BMJ. 1997;314(7094):1584-1588.

10. Vauthey C, de Freitas GR, van Melle G, Devuyst G, Bogousslavsky J. Better outcome after stroke with higher serum cholesterol levels. Neurology. 2000;54(10):19441949.

11. Zuliani G, Cherubini A, Atti AR, Ble A, Vavalle C, Di Todaro F, Benedetti C, et al. Low cholesterol levels are associated with short-term mortality in older patients with ischemic stroke. J Gerontol A Biol Sci Med Sci. 2004;59(3):293-297.

12. Olsen TS, Christensen RH, Kammersgaard LP, Andersen KK. Higher total serum cholesterol levels are associated with less severe strokes and lower all-cause mortality: ten-year follow-up of ischemic strokes in the Copenhagen Stroke Study. Stroke. 2007;38(10):2646-2651.

13. von Budingen HC, Baumgartner RW, Baumann CR, Rousson V, Siegel AM, Georgiadis D. Serum cholesterol levels do not influence outcome or recovery in acute ischemic stroke. Neurol Res. 2008;30(1):82-84.

14. Weir CJ, Sattar N, Walters MR, Lees KR. Low triglyc- 
eride, not low cholesterol concentration, independently predicts poor outcome following acute stroke. Cerebrovasc Dis. 2003;16(1):76-82.

15. Seo W, Oh H. Acute physiologic predictors of mortality and functional and cognitive recovery in hemorrhagic stroke: 1-, 3-, and 6-month assessments. J Stroke Cerebrovasc Dis. 2007;16(2):57-63.

16. Tirschwell DL, Smith NL, Heckbert SR, Lemaitre RN, Longstreth WT, Jr., Psaty BM. Association of cholesterol with stroke risk varies in stroke subtypes and patient subgroups. Neurology. 2004;63(10):1868-1875.

17. Censori B, Camerlingo M, Casto L, Ferraro B, Gazzaniga GC, Cesana B, Mamoli A. Prognostic factors in firstever stroke in the carotid artery territory seen within 6 hours after onset. Stroke. 1993;24(4):532-535.

18. Hsieh CL, Sheu CF, Hsueh IP, Wang CH. Trunk control as an early predictor of comprehensive activities of daily living function in stroke patients. Stroke. 2002;33(11):2626-2630.

19. Benaim C, Perennou DA, Villy J, Rousseaux M, Pelissier JY. Validation of a standardized assessment of postural control in stroke patients: the Postural Assessment Scale for Stroke Patients (PASS). Stroke. 1999;30(9):18621868.

20. Wang CH, Hsueh IP, Sheu CF, Hsieh CL. Discriminative, predictive, and evaluative properties of a trunk control measure in patients with stroke. Phys Ther. 2005;85(9):887-894.

21. Mao HF, Hsueh IP, Tang PF, Sheu CF, Hsieh CL. Analysis and comparison of the psychometric properties of three balance measures for stroke patients. Stroke. 2002;33(4):1022-1027.

22. Miyai I, Blau AD, Reding MJ, Volpe BT. Patients with stroke confined to basal ganglia have diminished response to rehabilitation efforts. Neurology. 1997;48(1):95-101.

23. Vatassery GT, Smith WE, Quach HT, Lai JC. In vitro oxidation of vitamin $\mathrm{E}$, vitamin $\mathrm{C}$, thiols and cholesterol in rat brain mitochondria incubated with free radicals. Neurochem Int. 1995;26(5):527-535.

24. Joseph JA, Villalobos-Molinas R, Denisova NA, Erat S, Strain J. Cholesterol: a two-edged sword in brain aging. Free Radic Biol Med. 1997;22(3):455-462.

25. Bastiaanse EM, van der Valk-Kokshoorn LJ, Egas-Kenniphaas JM, Atsma DE, van der Laarse A. The effect of sarcolemmal cholesterol content on the tolerance to anoxia in cardiomyocyte cultures. J Mol Cell Cardiol. 1994;26(5):639-648.

26. Amarenco P, Labreuche J, Elbaz A, Touboul PJ, Driss F, Jaillard A, Bruckert E. Blood lipids in brain infarction subtypes. Cerebrovasc Dis. 2006;22(2-3):101-108.

27. Kronmal RA, Cain KC, Ye Z, Omenn GS. Total serum cholesterol levels and mortality risk as a function of age. A report based on the Framingham data. Arch Intern Med. 1993;153(9):1065-1073.

28. Weverling-Rijnsburger AW, Blauw GJ, Lagaay AM, Knook DL, Meinders AE, Westendorp RG. Total cholesterol and risk of mortality in the oldest old. Lancet. 1997;350(9085):1119-1123.

29. Bagg S, Pombo AP, Hopman W. Effect of age on functional outcomes after stroke rehabilitation. Stroke. 2002;33(1):179-185.

30. Protopsaltis J, Kokkoris S, Korantzopoulos P, Milionis HJ, Karzi E, Anastasopoulou A, Filioti K, et al. Prediction of long-term functional outcome in patients with acute ischemic non-embolic stroke. Atherosclerosis. 2009;203(1):228-235.

31. Macciocchi SN, Diamond PT, Alves WM, Mertz T. Ischemic stroke: relation of age, lesion location, and initial neurologic deficit to functional outcome. Arch Phys Med Rehabil. 1998;79(10):1255-1257.

32. Musicco M, Emberti L, Nappi G, Caltagirone C. Early and long-term outcome of rehabilitation in stroke patients: the role of patient characteristics, time of initiation, and duration of interventions. Arch Phys Med Rehabil. 2003;84(4):551-558.

33. Weimar C, Ziegler A, Konig IR, Diener HC. Predicting functional outcome and survival after acute ischemic stroke. J Neurol. 2002;249(7):888-895.

34. Tilling K, Sterne JA, Rudd AG, Glass TA, Wityk RJ, Wolfe CD. A new method for predicting recovery after stroke. Stroke. 2001;32(12):2867-2873.

35. Kuptniratsaikul V, Kovindha A, Dajpratham P, Piravej K. Main outcomes of stroke rehabilitation: a multi-centre study in Thailand. J Rehabil Med. 2009;41(1):54-58.

36. Wang SL, Pan WH, Lee MC, Cheng SP, Chang MC. Predictors of survival among elders suffering strokes in Taiwan: observation from a nationally representative sample. Stroke. 2000;31(10):2354-2360.

37. Fukuda M, Kanda T, Kamide N, Akutsu T, Sakai F. Gender differences in long-term functional outcome after first-ever ischemic stroke. Intern Med. 2009;48(12):967973.

38. Reeves MJ, Bushnell CD, Howard G, Gargano JW, Duncan PW, Lynch G, Khatiwoda A, et al. Sex differences in stroke: epidemiology, clinical presentation, medical care, and outcomes. Lancet Neurol. 2008;7(10):915-926.

39. Turtzo LC, McCullough LD. Sex differences in stroke. Cerebrovasc Dis. 2008;26(5):462-474.

40. Kapral MK, Fang J, Hill MD, Silver F, Richards J, Jaigobin C, Cheung AM. Sex differences in stroke care and outcomes: results from the Registry of the Canadian Stroke Network. Stroke. 2005;36(4):809-814. 